\title{
Recent advances in high mobility donor-acceptor semiconducting polymers
}

\author{
Laure Biniek, ${ }^{*}$ Bob C. Schroeder, Christian B. Nielsen and Iain McCulloch \\ Department of Chemistry, Imperial College London, London SW7 2AZ, U.K. \\ E-mail: l.biniek@imperial.ac.uk
}

\begin{abstract}
A combination of improved understanding of molecular design criteria and polymer purification techniques, as well as optimised fabrication techniques and device surface treatments, have driven recent advances in the performance of semiconducting polymers for transistor applications. This development has allowed polymer-based devices to reach parity with the best values obtained for small molecule evaporated devices. Herein, we present the most recent work on solution processable high mobility donor-acceptor type polymers. We discuss the approaches that have been taken to improve both hole (and electron) mobility further. We will not only focus on chemical design criteria, but also describe certain processing approaches which have led to impressive hole mobilities of up to $5.5 \mathrm{~cm}^{2} / \mathrm{Vs}$.
\end{abstract}

\section{Introduction}

Early research in the field revealed that in the case of polythiophenes, when a $\pi$ stacked, lamellar microstructure was obtained through optimal processing and regioregularity within the molecular structure, charge carrier mobilities of the order of $0.1 \mathrm{~cm}^{2} / \mathrm{Vs}$ could be achieved. ${ }^{1}$ In this case, the plane of the polymer backbone was preferentially oriented orthogonal to the transport direction (i.e. the lamellae oriented in the plane). This characteristic morphology was shown to be further enhanced through liquid crystalline selfassembly promoting larger and more ordered domains ${ }^{2,3}$ with the result that mobilities could be increased to values approaching unity. ${ }^{4}$ For this kind of structure, the transport occurs 
within the two dimensional aromatic lamella. Subsequently, the improvement of the device air stability has been addressed by increasing the ionisation potential of the semiconducting polymer through the incorporation into the conjugated backbone of an electron deficient unit. For example, a bithiazole based copolymer has illustrated the potential of donor-acceptor alternating polymers for high charge carrier mobility materials by providing an air stable device with a hole mobility of $0.14 \mathrm{~cm}^{2} / \mathrm{Vs}^{5}$ It has recently been demonstrated that both highly polar diketopyrrolopyrrole (DPP) and benzothiadiazole (BT) containing donoracceptor polymers are able to afford even higher carrier mobilities, ${ }^{6,7,8}$ despite having apparently less ordered microstructures, and functional groups that have previously been expected to potentially act as charge traps. These results suggest that one dimensional charge transport along the polymer chains may dominate in these low ordered systems. This short highlight article attempts to collect and describe the literature reports since beginning of 2011.

\section{Discussion}

A series of results related to donor-acceptor type copolymers and their application in fieldeffect transistor (FET) devices have recently been published by Müllen et al. The alternating copolymer of cyclopentadithiophene (CPDT) and 2,1,3-benzothiadiazole (BT) (P1, Table 1) initially achieved a hole mobility of $0.17 \mathrm{~cm}^{2} / \mathrm{Vs}$ in FET devices, ${ }^{9}$ but through optimisation of the polymer's molecular weight and the device fabrication conditions, a higher hole mobility of $1.4 \mathrm{~cm}^{2} / \mathrm{Vs}$ was reported in $2009 .{ }^{10}$ Additional optimisation work from the same group afforded a thin film FET hole mobility of $3.3 \mathrm{~cm}^{2} / \mathrm{Vs}$, and subsequently an impressive value of $5.5 \mathrm{~cm}^{2} / \mathrm{Vs}$ was reported for a single fibre of $\mathbf{P 1} .^{12,13} \mathbf{P 2}$ with the large fused indacenodithiophene (IDT) motif was designed to have a planar, stiff backbone with low energetic disorder, thus promoting good transport properties. ${ }^{14}$ A series of different alkyl chain analogues of $\mathbf{P 2}$ were evaluated, and the best transistor performance was found with 
P2d (where $\mathrm{R}=$ hexadecyl) giving a hole mobility of $1.2 \mathrm{~cm}^{2} / \mathrm{Vs}$. The silicon analogue of IDT (Si-IDT) was reported in FET applications, ${ }^{25}$ with a similar approach adopted in the design of $\mathbf{P 3}$ and $\mathbf{P 4} .^{15}$ The longer $\mathrm{C}-\mathrm{Si}$ bond is expected to move the out-of-plane alkyl groups further away from the backbone and therefore promote stronger intermolecular interactions and more efficient $\pi$-stacking. ${ }^{11} \mathbf{P 3}$ afforded a hole mobility of $0.28 \mathrm{~cm}^{2} / \mathrm{Vs}$ after thermal annealing at $180^{\circ} \mathrm{C}$. With the introduction of fluorine atoms incorporated on the BT units in P4, favourable intramolecular sulphur-fluorine interactions were expected to help planarize the polymer backbone, but although a slightly higher degree of crystallinity was observed for $\mathbf{P 4}$ compared to $\mathbf{P 3}$, a slightly inferior hole mobility of $0.19 \mathrm{~cm}^{2} / \mathrm{Vs}$ was measured under identical processing conditions. Further elongation of the fused donor unit as in the case of $\mathbf{P 5}$ did not afford improved properties; the material was found to be amorphous and a lower hole mobility of $0.11 \mathrm{~cm}^{2} /$ Vs was reported. ${ }^{16}$

Quaterthiophenes with solubilising alkyl chains have also been used recently in donoracceptor type copolymers as illustrated by $\mathbf{P 6}$ and P7. With BT as the acceptor unit, Ong and co-workers achieved a FET hole mobility of $0.2 \mathrm{~cm}^{2} / \mathrm{Vs},{ }^{17}$ while Osaka and colleagues used the naphthobisthiadiazole acceptor and a slightly different quaterthiophene unit to fabricate a FET device with a maximum hole mobility of $0.55 \mathrm{~cm}^{2} / \mathrm{Vs} .{ }^{18}$ Interestingly, Osaka and coworkers found that the corresponding BT copolymer performed much worse $\left(0.074 \mathrm{~cm}^{2} / \mathrm{Vs}\right)$, which demonstrates that the substitution pattern on the quaterthiophene unit is of great importance for the molecular packing and consequently for the device properties. Another variation of BT, namely the benzobisthiadiazole, was used by Yuen and Wudl to afford polymer P8, which showed a hole mobility of $0.13 \mathrm{~cm}^{2} / \mathrm{Vs}$ after thermal annealing at $240^{\circ} \mathrm{C} .{ }^{19} \mathbf{P 8}$ was moreover found to have ambipolar properties as reflected in a maximum electron mobility of $0.10 \mathrm{~cm}^{2} / \mathrm{Vs}$, which closely matches the hole mobility. Yuen and Wudl 
also compared the CPDT unit to other donor moieties such as fluorene, dithienopyrrole and dithienosilole, all of which afforded polymers with much lower charge carrier mobilities.

Besides the various benzothiadiazole based donor-acceptor polymers, several polymers with repeat units based on classical dye designs, have shown exceptionally high mobilities recently. One class of these dye based polymers showing high mobilities is composed of two families, the well characterized diketopyrrolopyrrole (DPP) polymers and the more recently introduced indigo based polymers. Long branched alkyl side chains, which improve polymer solubility, were for a long time considered to be counterproductive to high mobility and to efficient $\pi-\pi$ stacking, for both steric and insulating reasons, but this hypothesis has been challenged with the introduction of DPP into the polymer backbone. In order to make DPP a viable unit in donor-acceptor polymers, long, branched and bulky 2-octyldodecyl side chains were attached to the otherwise insoluble DPP core, and high charge carrier mobilities were obtained despite the alkyl chain branching. Zhang et al. investigated a series of DPP polymers with various alkyl chain densities along the polymer backbone and they concluded that the organization of the polymer backbone is not necessarily interrupted by the presence of bulky and disordered side chains. ${ }^{8}$ Despite the sterically hindered side chains, hole mobilities of $0.6 \mathrm{~cm}^{2} / \mathrm{Vs}$ were obtained with $\mathbf{P 9}$ and the authors speculate that mostly local coplanar intermolecular associations and short contacts are responsible for these high mobility values while the overall orientation and crystallinity of the polymer is less crucial for charge transport. Li and co-workers synthesized a DPP-quaterthiophene copolymer (P10), which forms highly crystalline thin films despite the long bulky alkyl chains and hole mobilities of $0.97 \mathrm{~cm}^{2} / \mathrm{Vs}$ were achieved after mild annealing at $100{ }^{\circ} \mathrm{C}^{20}$ The introduction of thieno[3,2-b]thiophene further stiffens the polymer backbone and lowers the HOMO energy level. Chen et al. demonstrated balanced hole and electron mobilities exceeding $1 \mathrm{~cm}^{2} / \mathrm{Vs}$ for P11 by thoroughly optimizing the device architecture and material processing conditions. ${ }^{21}$ 
Jung et al. stiffened the polymer backbone further by introducing dithieno[3,2-b:2',3'd] thiophene, leading to a highly crystalline polymer P12. ${ }^{22}$ A high hole mobility of 0.68 $\mathrm{cm}^{2} /$ Vs could be measured for $\mathbf{P 1 2}$ and it is noteworthy that this high mobility could be obtained with as-spun films. Bronstein and co-workers designed and prepared thieno[3,2$b$ ]thiophene flanking groups for the DPP unit rather than the ubiquitous thiophene groups, thereby further extending the distribution of the HOMO energy level along the polymer backbone, and also further stiffening the backbone. ${ }^{7}$ The resulting polymer P13 achieved an impressive hole mobility of $1.95 \mathrm{~cm}^{2} / \mathrm{Vs}$ in top-gate/bottom-contact transistors without the need for high temperature annealing. It is interesting to note there was not a very high level of crystallinity observed.

Varying the neighbouring group of the 1,4-diketo-3,6-bis(thien-2-yl)pyrrolo[3,4-c]pyrrole (TDPP-T) core was demonstrated to have an impact on the polymer solubility, planarity, selfassembly properties and electronic structure. $\mathrm{Wu}$ et $a l$. investigated the effect of an arylvinylene linkage (P14) on DPP based polymers. ${ }^{23}$ Although the crystallinity of the TDPP-T based polymer was improved due to the rigidity of the arylenevinylene linkage, this did not change the hole mobility (measured at $0.2 \mathrm{~cm}^{2} / \mathrm{Vs}$ ). In order to increase the overall planarity of the conjugated backbone, two fused aromatic systems, naphthalene $(\mathbf{P 1 5})^{24}$ and Si-IDT $(\mathbf{P 1 6})^{25}$ were chosen as co-repeat units to be copolymerised with T-DPP-T. Due to strong intermolecular interactions and favourable $\pi$ - $\pi$ stacking, both polymers achieved a high hole mobility of $0.65 \mathrm{~cm}^{2} / \mathrm{Vs}$ after annealing at 120 and $200^{\circ} \mathrm{C}$ respectively. It is interesting to note that by changing the device architecture to a dual gate structure, the mobility of $\mathbf{P 1 5}$ could be further increased to $0.98 \mathrm{~cm}^{2} / \mathrm{Vs}$.

The introduction of selenophene into donor-acceptor type polymer backbones has recently attracted some interest including incorporation into DPP polymers. The substitution of thiophene with selenophene results in lower band-gap polymers, mainly due to the 
stabilisation of the polymer LUMO with little to no effect on the HOMO energy level. Shahid et al. reported the synthesis of selenophene analogues of polymer $\mathbf{P 9}$ and $\mathbf{P 1 1}{ }^{26}$ Initial charge carrier mobilities of $\mathbf{P 1 8}$ were rather low, but thermal annealing at $250^{\circ} \mathrm{C}$ and a change from bottom-contact to top-contact device configuration resulted in high ambipolar charge carrier mobilities (values of 1.1 and $0.15 \mathrm{~cm}^{2} / \mathrm{Vs}$ for hole and electron mobility, respectively), reported to be due to improved thin film organisation and reduced contact resistance. The lower hole mobility observed for $\mathbf{P 1 7}\left(0.1 \mathrm{~cm}^{2} / \mathrm{Vs}\right)$ may arise from poorer polymer backbone alignment normal to the substrate, as evidenced by X-ray diffraction studies. In addition to thermal treatment, Lin et al. tuned the thin film morphology of $\mathbf{P 1 9}$ by using high boiling solvents. ${ }^{27}$ By using high boiling 1,2,4-trichlorobenzene as solvent, the initial hole mobility of $0.12 \mathrm{~cm}^{2} / \mathrm{Vs}$, when spun from chloroform, could be increased to 1.62 $\mathrm{cm}^{2} / \mathrm{Vs}$. The authors explain this dramatic increase in mobility by the fact that the high boiling solvent evaporates slower from the polymer film, thus giving the polymer more time to self-assemble and form a dense network of organized polymer chains.

The substitution of thiophene by a furan ring in the polymer backbone led to a less crystalline polymer P20, even after thermal annealing at high temperature. ${ }^{28}$ Nevertheless, $\mathbf{P 2 0}$ showed a higher hole mobility $\left(1.54 \mathrm{~cm}^{2} / \mathrm{Vs}\right.$ after annealing at $\left.200^{\circ} \mathrm{C}\right)$ than the more crystalline thiophene polymer P10. With the introduction of naphthalene into the polymer backbone, reported by Sonar et al., a hole mobility of $0.11 \mathrm{~cm}^{2} / \mathrm{Vs}$ was achieved in a bottom gate/ top contact FET for $\mathbf{P 2 1},{ }^{29}$ lower than for the previously described thiophene analogue $\mathbf{P 1 5}{ }^{24}$

Most high mobility DPP polymers discussed so far have been obtained by co-polymerisation with thiophene-based donor units (or $\mathrm{O}$ and Se analogues). Having a thiophene based comonomer however is no necessity for high charge carrier mobility in FETs and a couple of high-performing BT-containing DPP polymers are described in the literature. P22 and P23 
differ only by the length of the solubilising alkyl chain and yet there are significant differences between the physical properties of the two polymers. Whereas P22, with 2octyldodecyl side chains, adopts an ordered lamellar structure in the solid state and a hole mobility of $0.53 \mathrm{~cm}^{2} / \mathrm{Vs}$ was obtained, ${ }^{30} \mathbf{P 2 3}$ with the slightly longer 2-decyltetradecyl chains is rather amorphous, which translates into a lower hole mobility of $0.1 \mathrm{~cm}^{2} / \mathrm{Vs}^{31}$ The selenophene analogue P24 has been reported very recently and exhibited high hole and electron mobilities of 0.46 and $0.84 \mathrm{~cm}^{2} / \mathrm{Vs}$ after thermal annealing at $200^{\circ} \mathrm{C}$ of the spincoated polymer film. ${ }^{32}$ The authors of the study suggest that inclusion of the more polarisable selenium atoms into the polymer backbone is responsible for the improved charge carrier mobilities of $\mathbf{P 2 4}$ compared to $\mathbf{P 2 2}$, rather than structural differences between the two polymers. Wudl and co-workers reported the co-polymerisation of DPP with benzobisthiadiazole (BBT) to afford P27. ${ }^{33}$ Due to the incorporation of the strong BBT acceptor, the resulting polymer shows ambipolar FET properties and impressive charge carrier mobilities reaching unity could be achieved after annealing at $240^{\circ} \mathrm{C}$ for both holes and electrons (1.17 and $1.32 \mathrm{~cm}^{2} / \mathrm{Vs}$ respectively).

Over the last year, isoindigo has been introduced as a building block for organic semiconducting materials. Similar to the well-known DPP, isoindigo is a pigment with an intramolecular dipole. Bao and co-workers were amongst the first to report a high mobility isoindigo based polymer $\mathbf{P 2 8} .^{34}$ A hole mobility of $0.79 \mathrm{~cm}^{2} / \mathrm{Vs}$, after annealing at $170^{\circ} \mathrm{C}$ was measured for $\mathbf{P 2 8}$, but the mobility could be dramatically increased by substituting the branched alkyl chains of $\mathbf{P 2 8}$ with siloxane terminated alkyl chains. Due to the presence of the siloxane groups the $\pi-\pi$ stacking distance of $\mathbf{P 2 9}$ is reduced to $3.58 \AA$, compared to 3.76 $\AA$ for P28, and a maximum hole mobility of $2.48 \mathrm{~cm}^{2} / \mathrm{Vs}$ was achieved. Ashraf et al. further fine tuned the isoindigo unit by substituting the flanking benzene rings with thiophenes, thus minimizing backbone twisting when polymerized with BT. $^{35}$ P30 exhibits excellent 
ambipolar characteristics with hole and electron mobilities exceeding $0.1 \mathrm{~cm}^{2} / \mathrm{Vs}$. Osaka et al. investigated another pigment, the quinacridone based polymer for FET applications and hole mobilities of $0.27 \mathrm{~cm}^{2} / \mathrm{Vs}$ were measured for $\mathbf{P 3 1} .^{36}$ Interestingly, the mobility seemed to be independent of polymer molecular weight and of orientational order, which the authors ascribe to limited electron delocalization along the polymer backbone.

\section{Conclusion}

It has become increasingly clear that the development of new semiconducting polymers is expanding from "conventional" nanocrystalline polymers with lamella morphologies, exemplified by polymers such as $\mathrm{P} 3 \mathrm{HT}$ and $\mathrm{pBTTT}$, to now also include donor-acceptor type polymers, with dipolar functionalities along the backbone. These high-performing polymers often incorporate strongly electron deficient units such as benzothiadiazole, or pyrrolidone with a high alkyl chain density. The alkyl chains are often oriented out of the plane of the polymer backbone, being grafted onto sp3-hybridised bridging atoms. It is remarkable that long branched alkyl chains do not seem to suppress efficient charge transport as seen especially for the DPP-containing polymers such as P13, P19 and P20. The most recent developments show that these alternating co-polymers can be excellent charge carriers and mobilities comparable to evaporated small molecules have already been achieved. Nevertheless, many are lacking long range order and crystallinity, which over many years have been the well-established criteria for high charge carrier mobilities. One of the possible explanations of this high mobility is that the intramolecular dipoles play a role in generating short contacts between chains. In the case of the polymers including extended $\pi$-planes motif, local coplanar intermolecular associations can also take place due to the local planarization and lead to these high mobility values. As outlined in this short highlight article, the field of high mobility polymers is progressing quickly with the continual development of new 
backbone designs and more advanced processing techniques. We believe that this trend will continue and that higher mobilities and more robust and commercially viable semiconducting polymers will be conceived in the near future. 


\section{Biography}

Laure Biniek is a research associate in the Chemistry Department at Imperial College London. She obtained her PhD in Chemistry from the University of Strasbourg in 2010. Her current research focuses on the design and synthesis of low band-gap light absorbing polymers with improved solar cell stability.

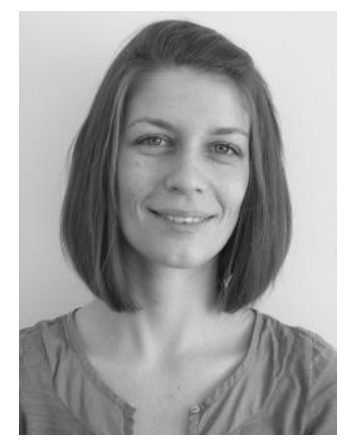

Bob C. Schroeder is currently a doctoral student in the Chemistry Department at Imperial College London. He received both his B. Sc. (2008) and M. Sc. (2010) in Chemistry from the Free University of Brussels (ULB). His current research focuses on the design and synthesis of novel organic semiconducting materials for applications in organic field effect transistors and photovoltaic devices. Bob is the recipient of a Fellowship from the National Research Fund of Luxembourg (FNR).

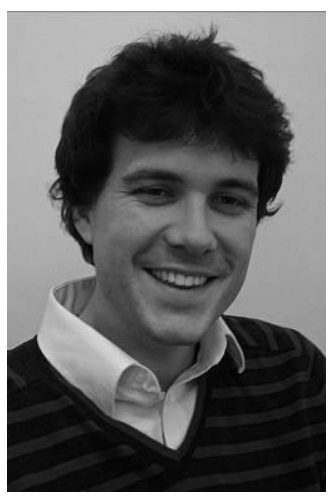


Christian B. Nielsen is a research associate in the Department of Chemistry at Imperial College London. He received his $\mathrm{PhD}$ in 2004 from the University of Copenhagen. His current research is focused on the design and synthesis of novel pi-conjugated materials aimed at the continued development of organic electronic applications such as field-effect transistors and solar cells.

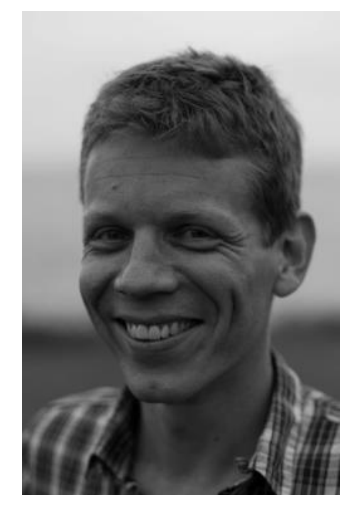

Iain McCulloch is Professor of Polymer Materials in the Department of Chemistry at Imperial College London, with research interests in organic semiconducting materials synthesis, characterization, and devices. He was previously the Organic Electronics Research Manager at Merck Chemicals. His achievements have been recognized with several awards including the Royal Society of Chemistry Creativity in Industry Prize.

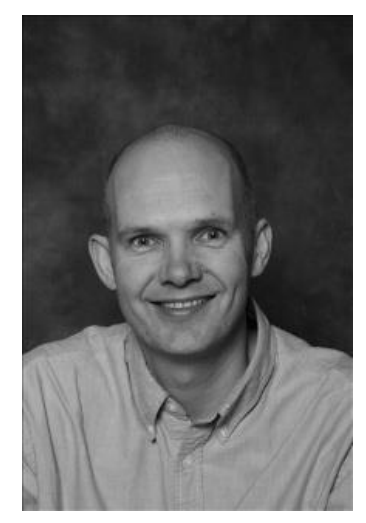




\begin{tabular}{|c|c|c|c|c|c|}
\hline Polymer structure & Reference & $\begin{array}{c}\max \mu_{\mathrm{h}}\left(\mathrm{cm}^{2} / \mathrm{Vs}\right) \\
\text { as spun/ after } \\
\text { annealing }(\mathrm{T})\end{array}$ & $\begin{array}{c}\mathbf{M}_{\mathrm{n}} / \mathbf{M}_{\mathbf{w}} \\
(\mathbf{k D a})\end{array}$ & $\begin{array}{l}\text { HOM } \\
\text { O }(e V)\end{array}$ & $\begin{array}{c}\text { Crystallinit } \\
y \\
\text { information }\end{array}$ \\
\hline $\mathrm{C}_{16} \mathrm{H}_{33} \mathrm{C}_{16} \mathrm{H}_{33}$ & $\begin{array}{l}{[12]} \\
{[13]}\end{array}$ & $-/ 5.5\left(200^{\circ} \mathrm{C}\right)$ & $50 /-$ & & 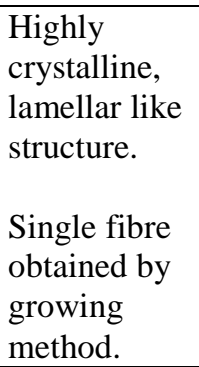 \\
\hline 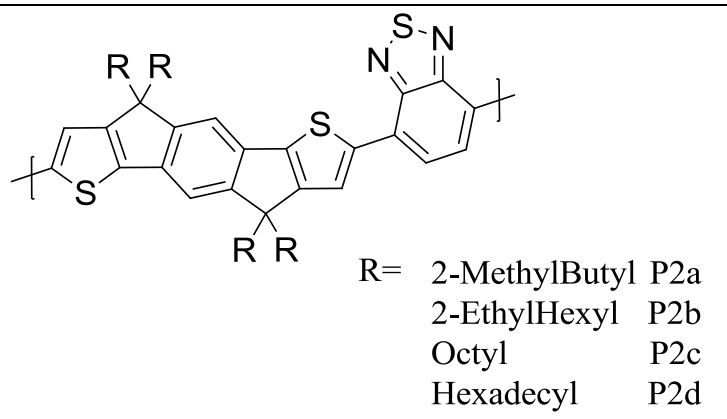 & $\begin{array}{l}{[14]} \\
\mathrm{P} 2 \mathrm{a} \\
\mathrm{P} 2 \mathrm{~b} \\
\mathrm{P} 2 \mathrm{c} \\
\mathrm{P} 2 \mathrm{~d}\end{array}$ & $\begin{array}{l}0.003 \\
0.57 \\
0.15 \\
1.2\end{array}$ & $\begin{array}{l}9 / 13 \\
40 / 87 \\
33 / 283 \\
38 / 108\end{array}$ & $\begin{array}{l}-5.3^{\mathrm{b}} \\
-5.3^{\mathrm{b}} \\
-5.3^{\mathrm{b}} \\
-5.4^{\mathrm{b}}\end{array}$ & \\
\hline (c) & $\begin{array}{l}{[15]} \\
\text { P3 } \\
\text { P4 }\end{array}$ & $\begin{array}{l}-/ 0.28\left(180^{\circ} \mathrm{C}\right) \\
-/ 0.19\left(180^{\circ} \mathrm{C}\right)\end{array}$ & $\begin{array}{l}22 / 56 \\
26 / 71\end{array}$ & $\begin{array}{l}-5.2^{\mathrm{a}} \\
-5.0^{\mathrm{b}} \\
-5.2^{\mathrm{a}} \\
-5.1^{\mathrm{b}}\end{array}$ & $\begin{array}{l}\text { Slightly } \\
\text { crystalline. }\end{array}$ \\
\hline $\mathrm{C}_{8} \mathrm{H}_{17} \widehat{C}_{\mathrm{C}_{8} \mathrm{H}_{17}}$ & [16] & $-/ 0.11\left(120^{\circ} \mathrm{C}\right)$ & $38 / 61$ & $-5.31^{\mathrm{a}}$ & Amorphous. \\
\hline $\mathrm{C}_{8} \mathrm{H}_{17}$ & [17] & $-/ 0.2\left(200^{\circ} \mathrm{C}\right)$ & $35 / 57$ & $-5.18^{\mathrm{a}}$ & Fibres. \\
\hline P7 & [18] & $\begin{array}{l}-/ 0.35\left(200^{\circ} \mathrm{C}\right) \\
\text { for HMDS } \\
\text { modified surface } \\
-/ 0.55\left(200^{\circ} \mathrm{C}\right) \text { for } \\
\text { FDTS modified } \\
\text { surface }\end{array}$ & $52.6 / 127$ & $-5.54^{\mathrm{a}}$ & $\begin{array}{l}\text { Semi- } \\
\text { crystalline } \\
\text { with a } \\
\text { predominant } \\
\text { edge-on } \\
\text { orientation. }\end{array}$ \\
\hline
\end{tabular}




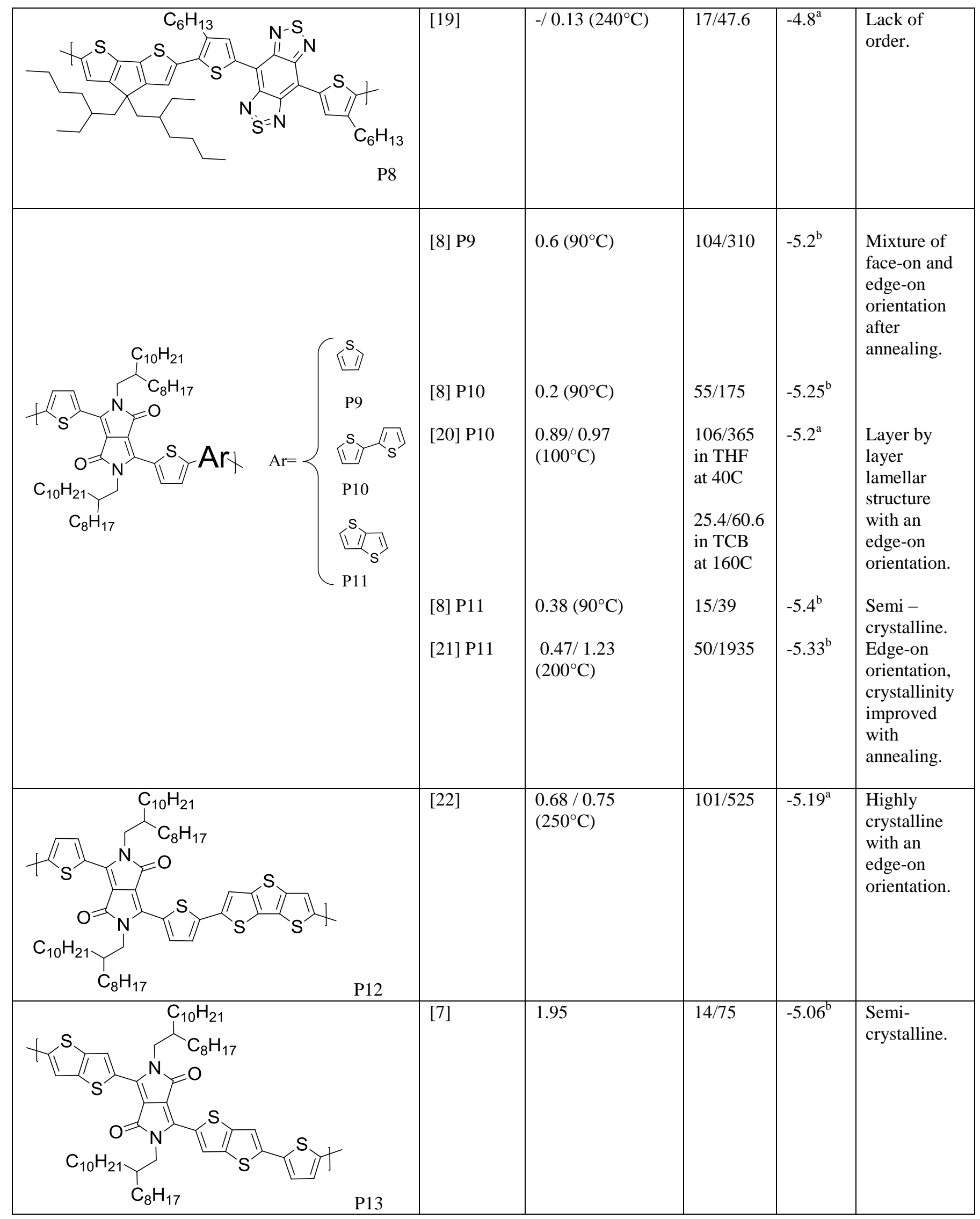




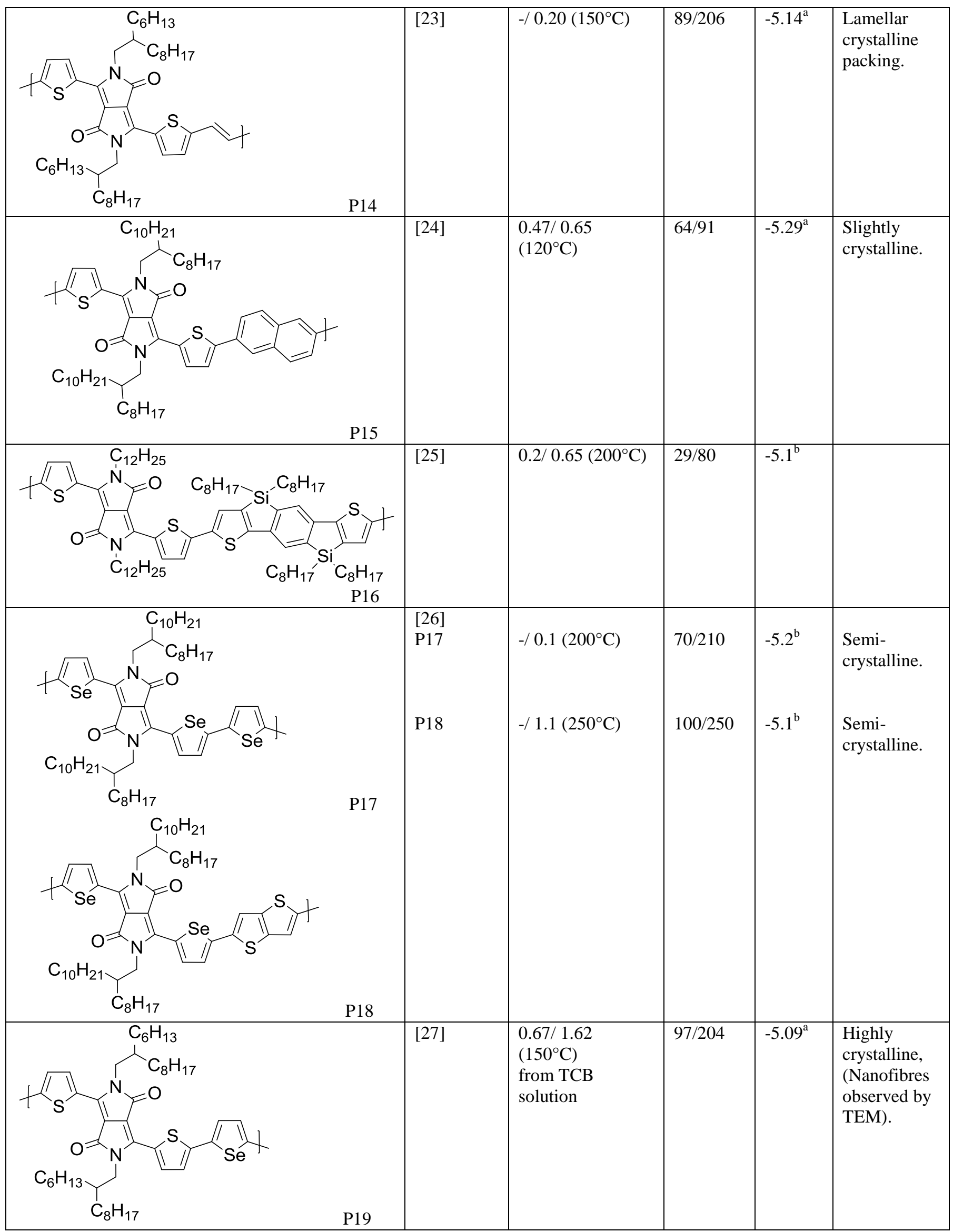




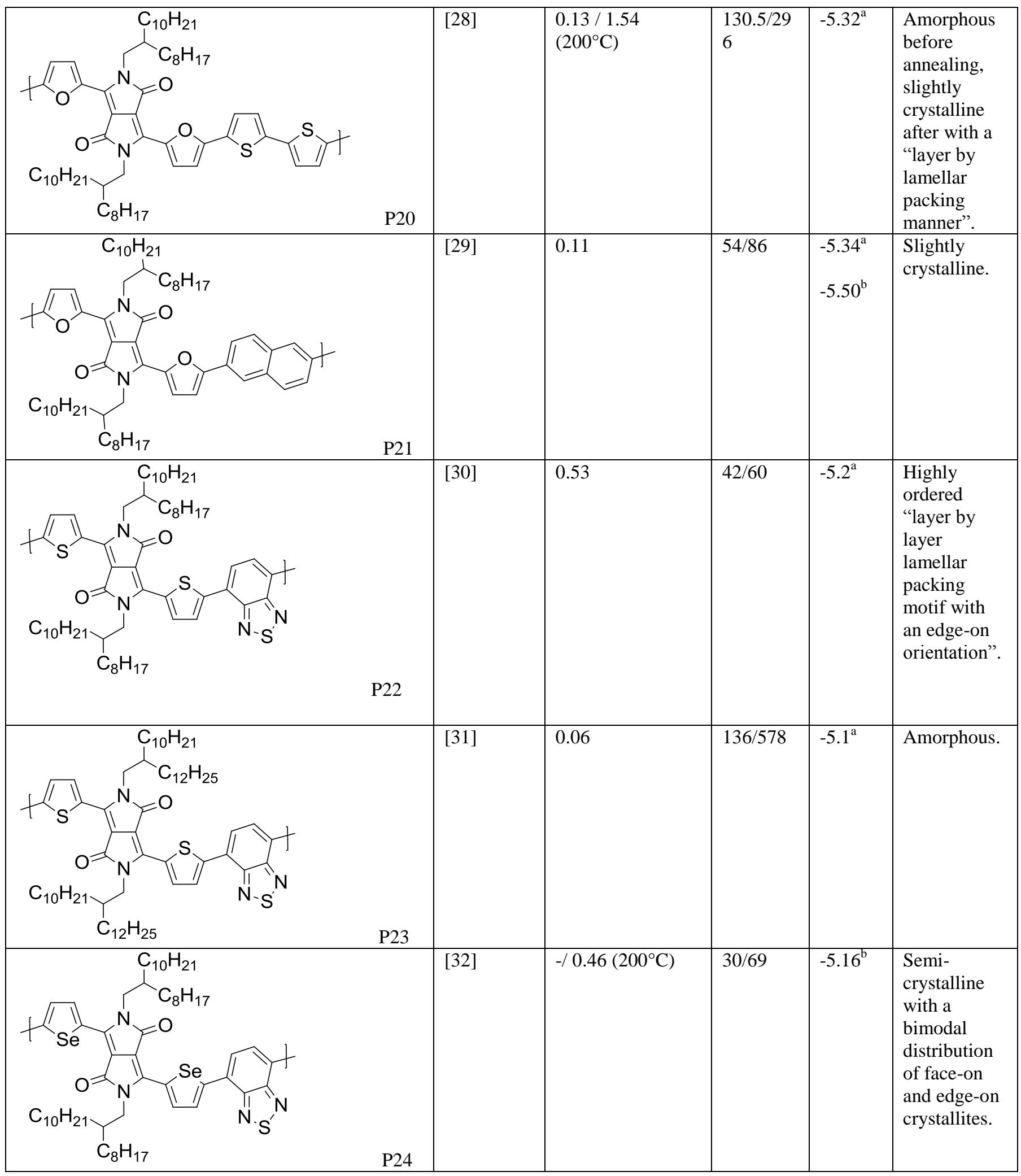




\begin{tabular}{|c|c|c|c|c|c|}
\hline (1) & P26 & $-/ 0.23\left(160^{\circ} \mathrm{C}\right)$ & $9.4 / 15$ & $\begin{array}{l}-4.7^{\mathrm{a}} \\
-4.75^{\mathrm{a}} \\
-4.55^{\mathrm{a}}\end{array}$ & $\begin{array}{l}\text { Lack of } \\
\text { crystallinity, } \\
\text { face-on } \\
\text { orientation. } \\
\text { Edge on } \\
\text { orientation, } \\
\text { more } \\
\text { crystalline } \\
\text { than P25. } \\
\text { Edge-on } \\
\text { orientation, } \\
\text { poorly } \\
\text { crystalline. }\end{array}$ \\
\hline 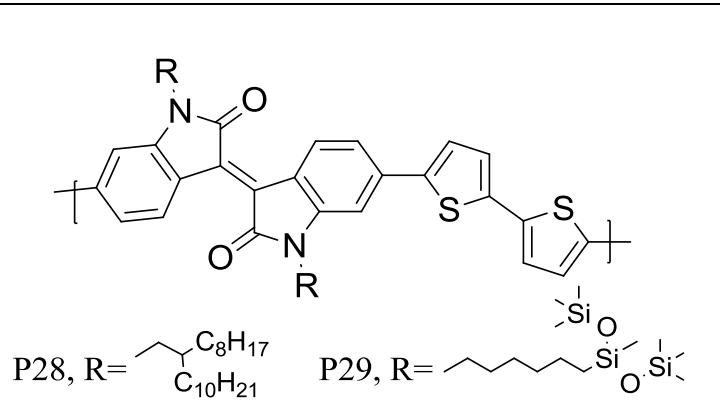 & $\begin{array}{l}\text { P28] } \\
\text { P28 } \\
\\
\text { P29 }\end{array}$ & $\begin{array}{l}0.2 / 0.79\left(170^{\circ} \mathrm{C}\right) \\
\\
0.45 / 2.48 \\
\left(170^{\circ} \mathrm{C}\right)\end{array}$ & $\begin{array}{r}135 / 742 \\
138 / 454\end{array}$ & $\begin{array}{l}-5.38^{\mathrm{b}} \\
-5.20^{\mathrm{b}}\end{array}$ & $\begin{array}{l}\text { Lamellar } \\
\text { packing both } \\
\text { in plane and } \\
\text { out of plane } \\
\text { orientation. }\end{array}$ \\
\hline (10) & [35] & $\begin{array}{l}0.16 / 0.15 \\
\left(250^{\circ} \mathrm{C}\right)\end{array}$ & $40 / 90$ & $-4.8^{b}$ & $\begin{array}{l}\text { Slightly } \\
\text { crystalline. }\end{array}$ \\
\hline (1) & [36] & $-/ 0.27\left(150^{\circ} \mathrm{C}\right)$ & $12 / 38$ & $-5.20^{\mathrm{a}}$ & $\begin{array}{l}\text { Highly } \\
\text { crystalline. }\end{array}$ \\
\hline
\end{tabular}

Table 1: Chemical structures and properties of the recent high hole mobility polymers. The highest hole mobility obtained on the as spun film and/or after annealing are mentioned here. The annealing temperature is indicated in brackets. The HOMO level has been estimated by ${ }^{a}$ Cyclicvoltammetry, ${ }^{b}$ photoelectron spectroscopy in air (PESA). 


\section{References}

[1] (a) H. Sirringhaus, P. J. Brown, R. H. Friend, M. M. Nielsen, K. Bechgaard, B. M. W. Langeveld-Voss, A. J. H. Spiering, R. A. J. Janssen, E. W. Meijer, P. Herwig, D. M. de Leeuw, Nature 1999, 401, 685-688; (b) D. M. DeLongchamp, B. M. Vogel, Y. Jung, M. C. Gurau, C. A. Richter, O. A. Kirillov, J. Obrzut, D. A. Fischer, S. Sambasivan, L. J. Richter, E. K. Lin, Chemistry of Materials 2005, 17, 5610-5612.

[2] I. McCulloch, M. Heeney, C. Bailey, K. Genevicius, I. MacDonald, M. Shkunov, D. Sparrowe, S. Tierney, R. Wagner, W. Zhang, M. L. Chabinyc, R. J. Kline, M. D. McGehee, M. F. Toney, Nature Materials 2006, 5, 328-333.

[3] B. S. Ong, Y. Wu, P. Liu, S. Gardner, J. Am. Chem. Soc. 2004, 126, 3378-3379.

[4] B. H. Hamadani, D. J. Gundlach, I. McCulloch, M. Heeney, Applied Physics Letters 2007, 91, 243512.

[5] J. Liu, R. Zhang, I. Osaka, S. Mishra, A. E. Javier, D.-M. Smilgies, T. Kowalewski, and R. D. McCullough, Adv. Funct. Mater. 2009, 19, 3427-3434.

[6] Z. Chen, M. J. Lee, R. S. Ashraf, Y. Gu, S. Albert-Seifried, M. Meedom Nielsen, B. Schroeder, T. D. Anthopoulos, M. Heeney, I. McCulloch, H. Sirringhaus, Adv. Mater. 2012, 24, 647-652.

[7] H. Bronstein, Z. Chen, R. S. Ashraf, W. Zhang, J. Du, J. R. Durrant, P. Shakya Tuladhar, K. Song, S. E. Watkins, Y. Geerts, M. M. Wienk, R. A. J. Janssen, T. Anthopoulos, H. Sirringhaus, M. Heeney, I. McCulloch, J. Am. Chem. Soc. 2011, 133, 3272-3275.

[8] X. Zhang, L. J. Richter, D. M. DeLongchamp, R. J. Kline, M. R. Hammond, I. McCulloch, M. Heeney, R. S. Ashraf, J. N. Smith, T. D. Anthopoulos, B. Schroeder, Y. H. Geerts, D. A. Fischer, M. F. Toney, J. Am. Chem. Soc. 2011, 133, 15073-15084.

[9] Zhang, M.; Tsao, H. N.; Pisula, W.; Yang, C.; Mishra, A. K.; Müllen, K. J. Am. Chem. Soc. 2007, 129, 3472.

[10] Tsao, H. N.; Cho, D.; Andreasen, J. W.; Rouhanipour, A.; Breiby, D. W.; Pisula, W.; Müllen, K. Adv. Mater. 2009, 21, 209.

[11] (a) M. C. Scharber, M. Koppe, J. Gao, F. Cordella, M. A. Loi, P. Denk, M. Morana, H.J. Egelhaaf, K. Forberich, G. Dennler, R. Gaudiana, D. Waller, Z. Zhu, X. Shi, C. J. Brabec, Adv. Mater. 2010, 22, 367-370; (b) H.-Y. Chen, J. Hou, A. E. Hayden, H. Yang, K. N. Houk, Y. Yang, Adv. Mater. 2010, 22, 371-375.

[12] H. N. Tsao, Do. M. Cho, I. Park, M. R. Hansen, A. Mavrinskiy, D. Y. Yoon, R. Graf, W. Pisula, H. W. Spiess, and K. Müllen, J. Am. Chem. Soc., 2011, 133 (8), 2605-2612.

[13] S. Wang, M. Kappl, I. Liebewirth, M. Müller, K. Kirchhoff, W. Pisula, and K. Müllen, Adv. Mater. 2012, 24, 417-420. 
[14] H. Bronstein, D. S. Leem, R. Hamilton, P. Woebkenberg, S. King, W. Zhang, R. Shahid Ashraf, M. Heeney, T. D. Anthopoulos, J. de Mello, and I. McCulloch, Macromolecules 2011, 44, 6649-6652.

[15] B. C. Schroeder, Z. Huang, R. S. Ashraf, J. Smith, P. D’Angelo, S. E. Watkins, T. D. Anthopoulos, J. R. Durrant, I. McCulloch, Adv. Funct. Mater. 2012, 22, 1663-1670.

[16] J.-S. Wu, Y.-J. Cheng, T.-Y. Lin, C.-Y. Chang, Pe.-I. Shih, and C.-S. Hsu, Adv. Funct. Mater. 2012, 22, 1711-1722.

[17] K.-H. Ong, S.-L. Lim, H.-S. Tan, H-K. Wong, J. Li, Z. Ma, L. C. H. Moh, S.-H. Lim, J. C. de Mello, and Z.-Kuan Chen, Adv. Mater. 2011, 23, 1409-1413.

[18] I. Osaka, M. Shimawaki, H. Mori, I. Doi, E. Miyazaki, T. Koganezawa, and K. Takimiya, J. Am. Chem. Soc. 2012, 134, 3498-3507.

[19] J. D. Yuen, R. Kumar, D. Zakhidov, J. Seifter, B. Lim, A. J. Heeger, and F. Wudl, Adv. Mater. 2011, 23, 3780-3785.

[20] Y. Li, P. Sonar, S. P. Singh, M. S. Soh, M. van Meurs, and J. Tan, J. Am. Chem. Soc. 2011, 133, 2198-2204.

[21] Z. Chen, M. J. Lee, R. S. Ashraf, Y. Gu, S. Albert-Seifried, M. Meedom Nielsen, B. Schroeder, T. D. Anthopoulos, M. Heeney, I. McCulloch, and H. Sirringhaus, Adv. Mater. 2012, 24, 647-652.

[22] J. W. Jung, F. Liu, T. P. Russell and W. H. Jo, Energy Environ. Sci. 2012, 5, 6857-6881.

[23] P.-T. Wu, F. S. Kim, and S. A. Jenekhe, Chem. Mater. 2011, 23, 4618-4624.

[24] P. Sonar, S. P. Singh, Y. Li, Z.-E. Ooi, T.-J. Ha, I. Wong, M. S. Soh, A. Dodabalapur, Energy Environ. Sci., 2011, 4, 2288-2296.

[25] R. S. Ashraf, Z. Chen, D. S. Leem, H. Bronstein, W. Zhang, B. Schroeder, Y. Geerts, J. Smith, S. Watkins, T. D. Anthopoulos, H. Sirringhaus, J. C. de Mello, M. Heeney, and I. McCulloch, Chem. Mater. 2011, 23, 768-770.

[26] M. Shahid, T. McCarthy-Ward, J. Labram, S. Rossbauer, E. B. Domingo, S. E. Watkins, N. Stingelin, T. D. Anthopoulos and M. Heeney, Chem. Sci., 2012, 3, 181-185.

[27] H.-W. Lin, W.-Y. Lee and W.-C. Chen, J. Mater. Chem., 2012, 22, 2120-2128.

[28] Y. Li, P. Sonar, S. P. Singh, W. Zeng and M. Si. Soh J. Mater. Chem., 2011, 21, 1082910835.

[29] Pr. Sonar, S. P. Singh, E. L. Williams, Y. Li, M. S. Soh and A. Dodabalapur, J. Mater. Chem. 2012, 22, 4425-4435. 
[30] (a) P. Sonar, S. P. Singh , Y. Li, M. S. Soh, and A. Dodabalapur, Adv. Mater. 2010, 22, pp 5409-5413. (b) T.-J. Ha, P. Sonar, B. Cobb, A. Dodabalapur, Organic Electronics, 2012, $13,136-141$.

[31] S. Cho, J. Lee, M. Tong, J. H. Seo, and C. Yang, Adv. Funct. Mater. 2011, 21, 19101916.

[32] A. J. Kronemeijer, E. Gili, M. Shahid, J. Rivnay, A. Salleo, M. Heeney, and H. Sirringhaus, Adv. Mater. 2012, 24, 1558-1565.

[33] J. D. Yuen, J. Fan, J. Seifter, B. Lim, R. Hufschmid, A. J. Heeger, and F. Wudl, J. Am. Chem. Soc. 2011, 133, 20799-20807.

[34] J. Mei, D. H. Kim, A. L. Ayzner, M. F. Toney, and Z. Bao, J. Am. Chem. Soc. 2011, 133, 20130-20133.

[35] R. S. Ashraf, A. J. Kronemeijer, D. James, H. Sirringhaus and I. McCulloch, Chem. Commun. 2012, 48, 3939-3941.

[36] I. Osaka, M. Akita, T. Koganezawa, and K. Takimiya, Chem. Mater. 2012, 24, 12351243. 